\title{
EVALUATION OF A SIMPLE TEST FOR DETERMINING HANDEDNESS
}

\author{
Ibrahim B. Syed, D.Sc., F.Inst.P., F.A.I.C., F.R.S.H. * Mubin Syed **
}

\section{Summary}

An analysis for handedness of 3,225 hand tracings submitted by the junior high school students from almost all the 48 states in continental United States was made. The results show that Mubin Syed's test predicts correctly about $74 \%$ of the time. But if one merely predicts everyone as right-handed, then one would be correct $89.3 \%$ of the time. It is possible that Mubin Syed's test is predicting correctly handedness rather than hand preference. However Mubin Syed's test shows promise in detecting left handed and ambixdextrous persons.

\section{Introduction}

It is generally accepted that the ability to write and to read depends upon the integrity of one of the cerebral hemispheres, the so-called dominant hemisphere; and that so does handedness, the superior skill of one hand over the other. ${ }^{\prime}$

The literature is filled with articles on hand preference and cerebral dominance and cortical lateralization. Hacaen and Sauguet studied cerebral dominance in left-handed subjects. ${ }^{2}$ A basic problem throughout the research has been the development of appropriate and reliable techniques for measurement of dominance. Cernacek ${ }^{3}$ devised a battery of 17 tests in each person to determine handedness. But Berman ${ }^{4}$ devised a battery of 30 tests in each person to determine handedness. Because of the supposed relationship between handedness and cerebral dominance and because of the implications of hemispheric dominance to research on language disorders, a simple yet sensitive test of handedness would be valuable. In this direction Simon ${ }^{5}$ investigated steadiness as an index of handedness.

A simple test for determining handedness was reported by the author earlier. ${ }^{6}$

\section{Materials and Methods}

After the publication of author's communication in the New England Journal of Medicine, ${ }^{\circ}$ it at-

\footnotetext{
"Medical Physicist, Nuclear Medicine Service VA Medical Center, 800 Zorn Avenue, Louisville, Kentucky 40202 and Clinical Professor of Medicine University of Louisville School of Medicine, Louisville, Kentucky 40232

"Premed student, Boston University, Boston, Mass.
}

tracted the attention of the Editor of Current Science which is exclusively read by junior high school students throughout the country. The Editor of Current Science, in an article on the test, asked the readers to check the test and to forward the results to him. ${ }^{7}$ The Editor in turn forwarded the results to this investigator.

The material forwarded showed the drawings of both the hands and the handedness of each student who participated in the experiment. Some gave their sex, grade in the school, separation (in inches or $\mathrm{cm}$ ) between paired fingers of each hand. Many analyzed their own results and commented upon whether their tests agreed or disagreed with Mubin Syed's findings.

More than 6,000 results were received. Of these 3,225 were selected for analysis as they gave full information including hand drawings and the handedness of the participant. Others were rejected due to lack of complete information on each participant. The participants were predominantly in the 7 th, 8 th, or 9 th grades. Both girls and boys participated. Almost all the 48 states in continental United States participated. Only the race of each participant is not known.

The test was already described. Same results could be obtained by measuring the distance between the little finger which is stretched away and the rest of the four fingers joined together (thumb, forefinger, middle finger and ring finger). This method appears to be visually significant and a better method than the one described earlier. ${ }^{\circ}$

\section{Results}

The results of the analysis are presented in Tables 1 and 2. Table 1 shows the prevalence of handedness among the 3,225 participants. 10.7 percent of the sample consists of left-handed persons and 89.3 percent are right-handed. 5.1 percent of the sample claimed to be ambidextrous, but they are classified as right or left-handed depending on their dominant hand. 95.2 percent of the ambidextrous persons are right-handed and only 4.8 percent are left-handed.

Table 2 shows that 72.8 percent of the righthanded agree with Mubin Syed's test. If the difference between one hand finger stretching over the other is less than equal to 10 percent, then that person is considered as ambidextrous. As 95.2 percent 
TABLE I

Prevalence of Handedness

Among

3,225 Junior High School Participants
Left

Right

Dominant hand: right

Dominant hand: left
HANDEDNESS

Ambidextrous *
NUMBER

PERCENT

345

2,880

165

157

8

$$
\begin{aligned}
\mathrm{P}(\mathrm{L} / \boldsymbol{\lambda}) & =\frac{\mathrm{P}(\boldsymbol{\lambda} / \mathrm{L}) \quad \mathrm{P}(\mathrm{L})}{\mathrm{P}(\boldsymbol{\lambda})} \\
& =\frac{\mathrm{P}(\boldsymbol{\lambda} / \mathrm{L}) \quad \mathrm{P}(\mathrm{L})}{\mathrm{P}(\boldsymbol{\lambda} / \mathrm{L}) \mathrm{P}(\mathrm{L})+\mathrm{P}(\boldsymbol{\lambda} / \mathrm{R}) \mathrm{P}(\mathrm{R})}=\frac{0.089666}{0.332562} \\
& =\frac{(0.838)(.107)}{(0.838(0.107)+(0.272)(0.893)} \\
& =0.2696
\end{aligned}
$$

As by-products one can also obtain

$\mathrm{P}(\boldsymbol{\lambda})=0.3326, \mathrm{P}(\boldsymbol{\rho})=0.6674$

and $\mathrm{P}(\mathrm{R} / \boldsymbol{\lambda})=1-\mathrm{P}(\mathrm{L} / \boldsymbol{\lambda})=0.7304$

$$
\mathrm{P}(\mathrm{L} / \boldsymbol{\rho})=1 \cdot \mathrm{P}(\mathrm{R} / \boldsymbol{\rho})=0.0260
$$

One can also calculate the probability that the test gives a correct prediction (call this event $\mathrm{C}$ ):

$$
\begin{aligned}
\mathrm{P}(\mathrm{C}) & =\mathrm{P}[(\boldsymbol{\rho} \& \mathrm{R}) \text { or }(\boldsymbol{\lambda} \& \mathrm{~L})] \\
& =\mathrm{P}(\boldsymbol{\rho} \& \mathrm{R})+\mathrm{P}(\boldsymbol{\lambda} \& \mathrm{~L}) \\
& =\mathrm{P}(\boldsymbol{\rho} / \mathrm{R} \mathrm{P}(\mathrm{R})+\mathrm{P}(\boldsymbol{\lambda} / \mathrm{L}) \mathrm{P}(\mathrm{L}) \\
& =(0.728)(0.893)+(0.838(0.107) \\
& =0.650104+0.08966 \\
& =0.73977
\end{aligned}
$$

That is Mubin Syed's test predicts correctly about $74 \%$ of the time.

\section{Discussions}

As shown earlier, Mubin Syed's test predicts correctly about $74 \%$ of the time. But if one merely predicts everyone as right-handed, then one would be correct $89.3 \%$ of the time which is close to the $90 \%$ accuracy suggested by Bersohn ${ }^{2}$. But it is possible that Mubin Syed's test is predicting correctly handedness rather than hand preference. ${ }^{5}$ It is a well-known fact that all over the world including United States children who are left-handed are forced to change to right-handedness.

However Mubin Syed's test shows promise in detecting ambidextrous persons, $95.2 \%$ of whom are right-handed due to reasons stated earlier.

By merely predicting everyone as left-handed, one would be correct $10.7 \%$ of the time. In contrast Mubin Syed's test merits in predicting left-handed people correctly in about $74 \%$ of the time. A simple test is not available to match the performance of Mubin Syed's test in predicting left-handed and ambidextrous people.

Preliminary observations showed that people in tension states may not be able to spread their fingerpairs as widely as those who are not; this was especially noted with the females tested ${ }^{10}$. One could be relatively certain that pressure-sensitive transducers would probably show differences between tense and nontense people. However, 
whether it would be worthwhile to pursue this approach now is a diffrent question.

Mubin Syed's test could be used for lateral dominance screening of children at the beginning of the first grade. But Balow" says such screening will not provide the teacher with information which will help to spot those children who are likely to have difficulty in learning to read.

\section{References}

1. Reinhold, M., Proceed. Royal Soc. Med. 1963, 56, 203.

2. Hecaen and Sanguet, J., Cortex, 1971, 7, 19.

3. Cernacek, J., J. Neurol. Sci. 1964, 1, 152.

4. Berman, A., Cortex, 1971, 7, 372.

5. Simon, J.R., Perceptual and Motor Skills, 1964, 18, 203.

6. Syed, I.B., N. Engl. J. Med. 1973, 289, 1205.

7. Catalyst, Current Science, 1974, 59, (19), 8.

8. Scheuer, E.M., Personal Communication, 1974.

9. Bersohn, M.M., N. Engl. J. Med., 1974, 291, 801.

10. Rapp, M.S., Personal Communication, 1974.

11. Balo, 1.H., J. Pschol. 1963, 55, 323.

\section{Acknowledgements}

The author wishes to thank the following individuals and organizations for their support, interest and encouragement:
Mr. Joseph W. Bradley, Director of Public Relations, Baystate Medical Center, Springfield, Massachusetts

The Editor and Publisher of Springfield union Newspaper, Springfield, Massachusetts.

The Associated Press.

Mr. Vincent Marteka, Editor of Current Science, a Xerox Education Publication, Middletown, CT 06457 .

Finally to all the teachers and students throughout the continental United States who so enthusiastically participated in testing Mubin Syed's test for handedness.

Requests for reprints should be addressed to

Ibrahim B. Syed, D.Sc.

800 Zorn Avenue

Louisville, Ky, 40202 